Original Article

\title{
Outcome of Deep Brain Stimulation (DBS) for the Treatment of Parkinson's Disease in Terms of Improvement in MDS-UPDRS Scale Over 5 Years
}

\author{
Khalid Mahmood, Omair Afzal Ali, Adeeb-ul-Hassan, Imran Ali
}

Punjab Institute of Neurosciences (PINS), Lahore - Pakistan

\begin{abstract}
Background \& Objective: Parkinson's disease (PD) is the second most common Neurodegenerative disorder after Alzheimer's disease. There are several surgical procedures for advanced PD, but amongst all deep brain stimulation has proven to be safest and effective. The objective of this study was to see the outcome of DBS for the treatment of PD in terms of improvement in MDS UPDRS over 5 years.
\end{abstract}

Material and Methods: 44 patients were included in study from Oct 2014 to Sep 2019. History, examination was carried out, and preoperative MDS-UPDRS (Movement Disorder Society Unified Parkinson's Disease Rating Scale) was recorded. Postoperative improvement in MDS-UPDRS score was assessed at first Programming, $2^{\text {nd }}$ week, and 6 th week and at $3^{\text {rd }}$ month.

Results: At baseline the mean, the MDS - UPDRS (Part-I) score was $14.20 \pm 0.61$ and at the end of $3^{\text {rd }}$ month, the mean score was $11.18 \pm 0.47$ respectively. At baseline the mean, the MDS - UPDRS (part-II) score was $18.99 \pm 0.70$ and at the end of $3^{\text {rd }}$ month, the mean score was $13.01 \pm 0.57$, respectively. At baseline the mean, the MDS - UPDRS (part-III) score was $45.19 \pm 0.90$ and at the end of $3^{\text {rd }}$ month, the mean score was $25.15 \pm 1.20$ respectively. At baseline the mean, the MDS - UPDRS (part-IV) score was $10.18 \pm 0.87$ and at the end of $3^{\text {rd }}$ month, the mean score was $3.85 \pm 1.03$, respectively. One patient developed post-operative $\mathrm{ICH}$ (intracerebral hemorrhage), which resolved after 1 month.

Conclusion: The Deep Brain Stimulation (DBS) is safe and effective in the management of PD.

Keywords: Deep Brain Stimulation (DBS), MDS-UPDRS (Movement Disorder Society Unified Parkinson's Disease Rating Scale), Globus Pallidus (GPi), Subthalamic Nucleus (STN), and Parkinson's disease.

Corresponding Author: Adeeb-ul-Hassan

Punjab Institute of Neurosciences (PINS) Lahore, Pakistan.

Email: pinslahore@gmail.com

Date of Submission: 07-11-2020

Date of Revision: 15-12-2020

Date of Online Publishing: 25-12-2020

Date of Print: $30-12-2020$
DOI: $10.36552 /$ pjns.v24i4.498

\section{INTRODUCTION}

Amongst neurodegenerative diseases, Parkinson's disease is ranked second after Alzheimer's disease. There are many contributing risk factors, 
some are environmental and some genetic ${ }^{1}$.It manifests as bradykinesia, rigidity, resting tremor and postural instability. ${ }^{2}$ Prevalence of Parkinson's disease (PD) is low in Asian countries, but universally it ranges from 0.012 to $12.5 \%$ and the incidence ranges from 15 per hundred thousand to 328 per hundred thousand. ${ }^{2}$

The medical treatment options, which are available only providing the symptomatic relief, but do not affect neuronal loss.Most of these patients do not remain stable on these medications and they develop dyskinesias and motor fluctuations. Usually, thenon-motor symptoms do not respond well to dopaminergic replacement therapies. ${ }^{4}$ Patients with Parkinson's disease regularly have quick swings among versatility and idleness, and many react inadmissible to changes in pharmacological treatment. $^{3}$

Advancements in Stereotactic technology have led to a lot of developments in the management of Parkinson's disease. 3 Previously, the surgical options available were stereotactic lesioning (Pallidotomy and Thalamotomy) having disadvantage of permanent lesioning. In 1987, the deep brain high frequency stimulation of the thalamus was experimented to treat tremors. In 1993, it was tested for sub-thalamic nucleus to treat advanced cases of Parkinson's disease.In Pakistan first Deep Brain stimulation surgery was conducted at Lahore General Hospital (LGH) in 2013. High-frequency stimulation of the subthalamic nucleus has become the surgical therapy of choice. ${ }^{4}$ DBS is an effective surgical treatment for Parkinson's disease on the other hand it may have some complications which are operation related, hardware related and stimulation related.

The target of choice for DBS is the subthalamic nucleus (STN), many studies, has underlined the efficacy of STN Deep Brain Stimulation (DBS). The Globus Pallidus is the second most frequent target, although supported to a lesser extent by controlled studies. ${ }^{5}$

MDS-UPDRS representing a compound measure of the disease severity with different subscales. The four cardinal symptoms - rigidity, tremor, bradykinesia, and postural instability - are scored by the UPDRS part III, whereas mentation, mood, and behavior (part I), activities of daily living (part II), and dyskinesia (part IV) are scored separately. Higher values indicate more severe symptoms; thus, increasing values are connected exponentially with symptom severity. Standardized assessments are used by the vast majority of studies. ${ }^{6}$

\section{MATERIAL AND METHODS}

\section{Study Design}

Prospective obstructive study.

\section{Inclusion Criteria}

From Oct 2014 to Sep 2019, 44 patients with advanced Parkinson's disease were enrolled in the study from PINS (Punjab Institute of Neurosciences), Lahore. After endorsement from hospital ethical committee, all patients satisfying the inclusion criteria were included in the study. The procedure was explained and informed consents were taken from all the patients or attendants to use their data for research purposes.

\section{Inclusion Criteria}

Primary Parkinson's disease, which is medically refractory (carbidopa $200 \mathrm{mg} /$ day and Levodopa $800 \mathrm{mg} /$ day) for at least 6 months. We enrolled patient's withno structural lesion on MRI Brain, and those who reported the absence of dementia.

\section{Excluding Criteria}

Patients were excluded who were with Atypical/ Secondary Parkinsonism and advanced 
Parkinson's disease (wheel chair/bedbound or dementia).

\section{Data Collection}

Proper history and examination were carried out, and preoperative MDS- UPDRS (Movement Disorder Society Unified Parkinson's Disease Rating Scale), was recorded. Blood investigations via., CBC, LFTs, RFTs, APTT, and PT/INR was done. All the Parkinsonian drugs were stopped one day before surgery.

\section{Surgical Procedure}

In the operation theatre, a stereotactic frame (Leksell G frame) was applied to the patient's head.The patient was transferred to MRI department and MRI Brain is obtained. The images were then transferred to Surgi Plan/Frame link (as we are using two work stations in our department) workstation. The images were first defined, then looking on the mid-sagittal cuts anterior commissure and Posterior commissure was defined and AC-PC line was drawn between these two points. This acquired target was further confirmed by super imposing Shelton Brain digital brain atlas. Once the desired target was confirmed the path to hit that target was determined. The whole computerized calculation was printed and carried to the operation theatre for surgery. The Leksell frame was attached on head end of the OT table with an attachment to fix the head during surgery. Head end was liftedup to 30 degrees. Head shave of the patient was done. Arc and Rings were attached to the frame according to the calculations, and $X, Y$ and $Z$ of the frame were adjusted. Pyodine solution and local anesthetic solution were applied at the site for skin incision. A 14-mm bur hole was placed and dura opened. For STN, MER (Micro electrode Recording) is performed using the Microdrive, microelectrodes and Inomed Machine. The patient was evaluated by a neurologist for assessment of tremors/rigidity and any capsular side effects. The area of maximal therapeutic benefit was recorded and DBS lead is measured so that the distal contact lies just below the noted area.

The second stage of the operation was performed under general anesthesia. The proximal ends of the DBS leads connected, to an implantable pulse generator, which was placed in an infraclavicular subcutaneous pocket on right side of chest. The pre-op medications for Parkinsonism, which were stopped were restarted. A post op CT scan brain plain was performed to see the placement of leads and to see any complication. The patient was evaluated in the next morning and MDS-UPDRS noted. Patients were then discharged and asked to come after two weeks for stitch removal and programming.

\section{Programming}

IST programming was done two weeks after surgery in which voltage, Frequency and pulse width were adjusted to alleviate patient symptoms. The patient may need a couple of programming sessions. Programming sessions are conducted by a Neurosurgeon and a Neurologist at our Center. MDS-UPDRS noted at Post Programming, 2 weeks, 6 weeks and 3 months to see improvement in MDS-UPDRS score.

\section{Data Analysis}

Data was statistically analyzed using SPSS 26. Variables were identified. Simple descriptive statistics were used for analysis of demographic variables. Mean and standard deviations were calculated for age, frequencies and percentages were determined for qualitative variables that are gender, post-operative complications, mortality, morbidity and hospital stay. Paired t-test were applied. 


\section{RESULTS}

\section{Age Distribution}

The mean age of patients was $67.07 \pm 9.45$ years with minimum and maximum age as 50 and 80 years.

\section{Gender Incidence}

There were 29 (65.9\%) male and 15 (34.09\%) female cases with male to female ratio as $2: 1$.

\section{Outcome}

At baseline, the mean MDS UPDRS (part-I) score was $14.20 \pm$ 0.61 , at $2^{\text {nd }}$ week, the score was $13.78 \pm 0.56$, at $6^{\text {th }}$ week the score was $12.72 \pm 0.68$ and at the end of $3^{\text {rd }}$ month, the mean score was $11.18 \pm 0.47$, respectively.

On applying paired sample ttest, a significant reduction in MDS-UPDRS score was found when compared at different follow-ups, $p$-value $\leq 0.001$. Overall, the decrease in MDSUPDRS score (Part-I) was statistically significant.

At baseline, the mean MDS UPDRS (part-II) score was 18.99 \pm 0.70 , at $2^{\text {nd }}$ week the score was $18.58 \pm 0.84$, at $6^{\text {th }}$ week the score was $15.93 \pm 0.57$ and at the end of $3^{\text {rd }}$ month the mean score was $13.01 \pm 0.57$ respectively. There was significant reduction in MDSUPDRS score when compared with different follow-ups, $p$-value $<0.05$ except baseline versus 2
Table 1: Comparison of MDS-UPDRS (Part-I) score at different followups.

\begin{tabular}{|lccccc|} 
MDS-UPDRS (part-I) & Mean & S.D & Range & Minimum & Maximum \\
At baseline & 14.20 & 0.61 & 1.90 & 13.10 & 15.00 \\
At 2 weeks & 13.78 & 0.56 & 2.20 & 12.80 & 15.00 \\
At 6 weeks & 12.72 & 0.68 & 2.00 & 11.50 & 13.50 \\
At 3 month & 11.18 & 0.47 & 1.30 & 10.50 & 11.80 \\
\hline
\end{tabular}

Table 2: Comparison of MDS-UPDRS (Part-I) score at different followups (F-test value $=22302.013$ ).

\begin{tabular}{lccc|} 
MDS-UPDRS (part-I) & $\mathbf{t}$ & $\mathbf{d f}$ & p-value \\
Baseline versus 2 weeks & 4.063 & 14 & 0.001 \\
Baseline versus 6 weeks & 7.320 & 14 & $<0.001$ \\
Baseline versus 3 months & 14.363 & 14 & $<0.001$ \\
2 weeks versus 6 weeks & 4.284 & 14 & 0.001 \\
2 weeks versus 12 months & 13.560 & 14 & $<0.001$ \\
6 weeks versus 12 months & 6.736 & 14 & $<0.001$ \\
\hline
\end{tabular}

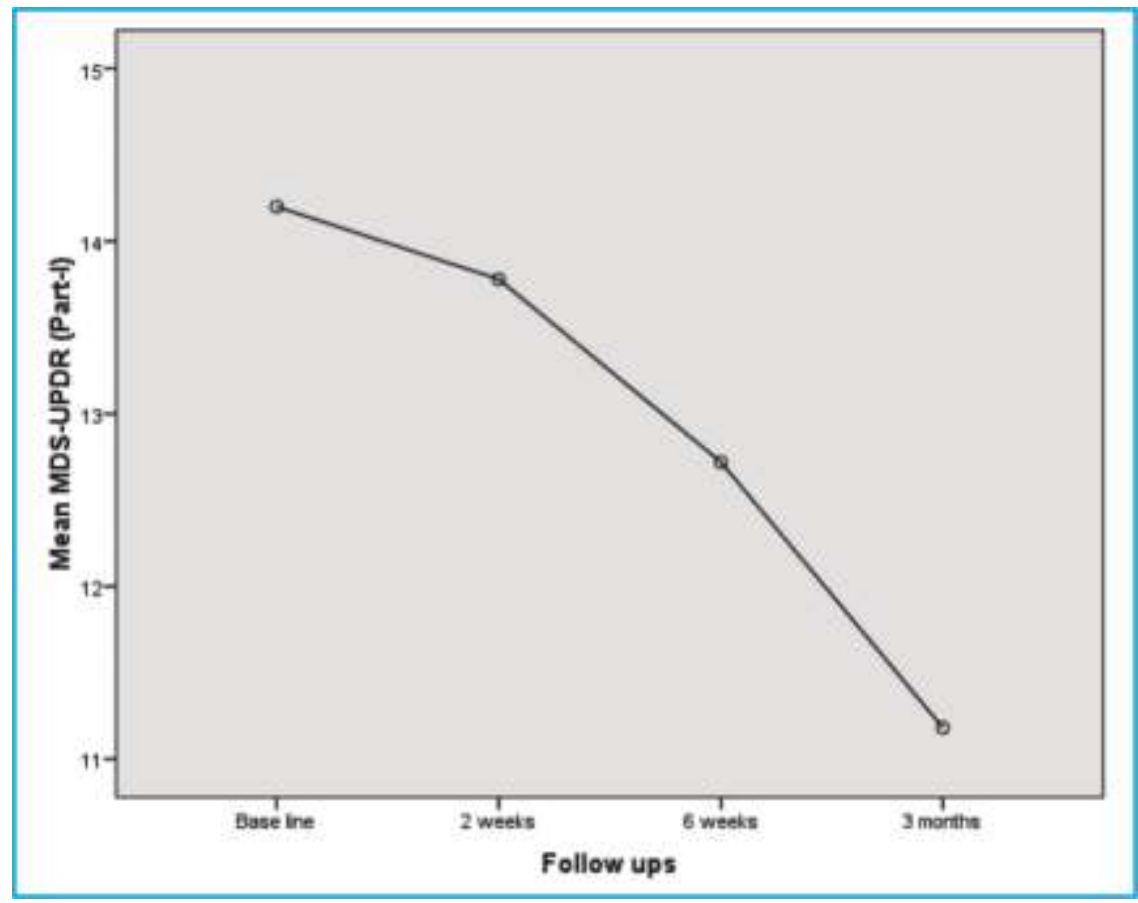

Figure 1: Graphical Comparison of MDS-UPDRS (Part-I) score at different follow-ups. 
weeks, p-value > 0.05. Overall, the decrease in MDS-UPDRS score (Part-II) was statistically significant.
Table 3: Comparison of MDS-UPDRS (part-II) score at different followups.

\begin{tabular}{|lccccc|} 
MDS-UPDRS (part-II) & Mean & S.D & Range & Minimum & Maximum \\
At baseline & 18.99 & 0.70 & 1.90 & 18.10 & 20.00 \\
At 2 weeks & 18.58 & 0.84 & 2.70 & 17.30 & 20.00 \\
At 6 weeks & 15.93 & 0.57 & 1.90 & 15.00 & 16.90 \\
At 3 month & 13.01 & 0.57 & 1.70 & 12.20 & 13.90 \\
\hline
\end{tabular}

Table 4: Comparison of MDS-UPDRS (part-II) score at different followups (F-test $=26070.056)$.

\begin{tabular}{lccc|} 
MDS-UPDRS (part-II) & $\mathbf{t}$ & $\mathbf{d f}$ & $\mathbf{p}$-value \\
Baseline versus 2 weeks & 1.629 & 14 & 0.126 \\
Baseline versus 6 weeks & 16.196 & 14 & $<0.001$ \\
Baseline versus 3 months & 23.568 & 14 & $<0.001$ \\
2 weeks versus 6 weeks & 12.720 & 14 & $<0.001$ \\
2 weeks versus 12 months & 19.697 & 14 & $<0.001$ \\
6 weeks versus 12 months & 15.892 & 14 & $<0.001$ \\
\hline
\end{tabular}

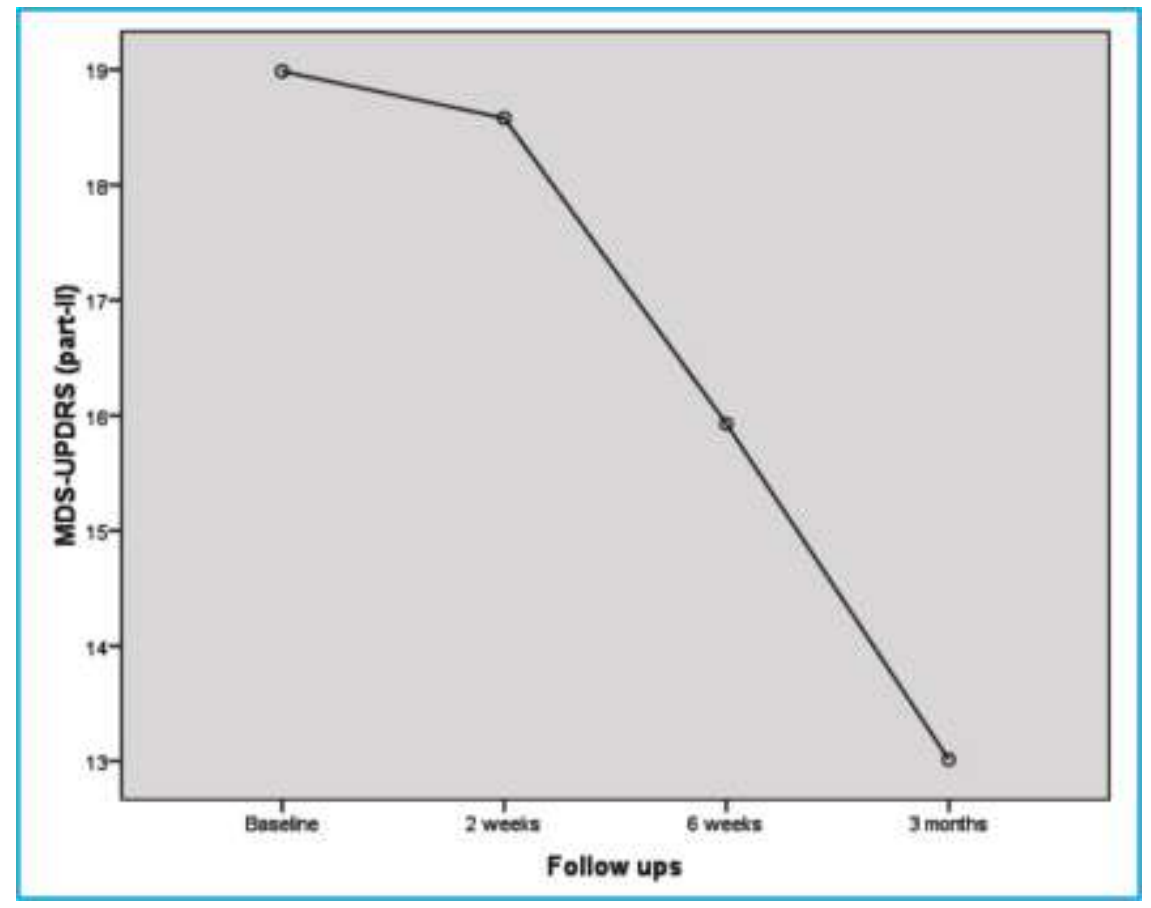

Figure 2: Graphical Comparison of MDS-UPDRS (part-II) score at different follow-ups. 
At baseline, the mean MDS UPDRS (part-III) score was 45.19 \pm 0.90 , at $2^{\text {nd }}$ week, the score was $44.92 \pm 0.65$, at $6^{\text {th }}$ week, the score was $36.49 \pm 0.74$ and at the end of $3^{\text {rd }}$ month, the mean score was $25.15 \pm 1.20$, respectively. There was significant reduction in MDSUPDRS score, when compared with different follow-ups, $p$-value $<0.05$ except baseline versus 2 weeks, p-value > 0.05. Overall the decrease in MDS-UPDRS score (Part-III) was statistically significant.
Table 5: Comparison of MDS-UPDRS (part-III) score at different followups.

\begin{tabular}{lccccc|} 
MDS-UPDRS (part-III) & Mean & S.D & Range & Minimum & Maximum \\
$\begin{array}{l}\text { At baseline } \\
\text { (Off Medication) }\end{array}$ & 45.19 & 0.90 & 2.90 & 44.00 & 46.90 \\
$\begin{array}{l}\text { At 2 weeks } \\
\text { (On Medication) }\end{array}$ & 44.92 & 0.65 & 1.90 & 44.00 & 45.90 \\
$\begin{array}{l}\text { At 6 weeks } \\
\text { (On Medication) }\end{array}$ & 36.49 & 0.74 & 2.90 & 35.10 & 38.00 \\
$\begin{array}{l}\text { At 3 month } \\
\text { (On Medication) }\end{array}$ & 25.15 & 1.20 & 4.50 & 22.50 & 27.00 \\
\hline
\end{tabular}

Table6: Comparison of MDS-UPDRS (part-III) score at different followups (F-test $=139540.614)$.

\begin{tabular}{|lccc|}
\hline MDS-UPDRS (part-III) & $\mathbf{t}$ & $\mathbf{d f}$ & p-value \\
\hline Baseline versus 2 weeks & 0.769 & 14 & 0.455 \\
Baseline versus 6 weeks & 26.326 & 14 & $<0.001$ \\
Baseline versus 3 months & 53.024 & 14 & $<0.001$ \\
2 weeks versus 6 weeks & 43.011 & 14 & $<0.001$ \\
2 weeks versus 12 months & 55.032 & 14 & $<0.001$ \\
6 weeks versus 12 months & 29.482 & 14 & $<0.001$ \\
\hline
\end{tabular}

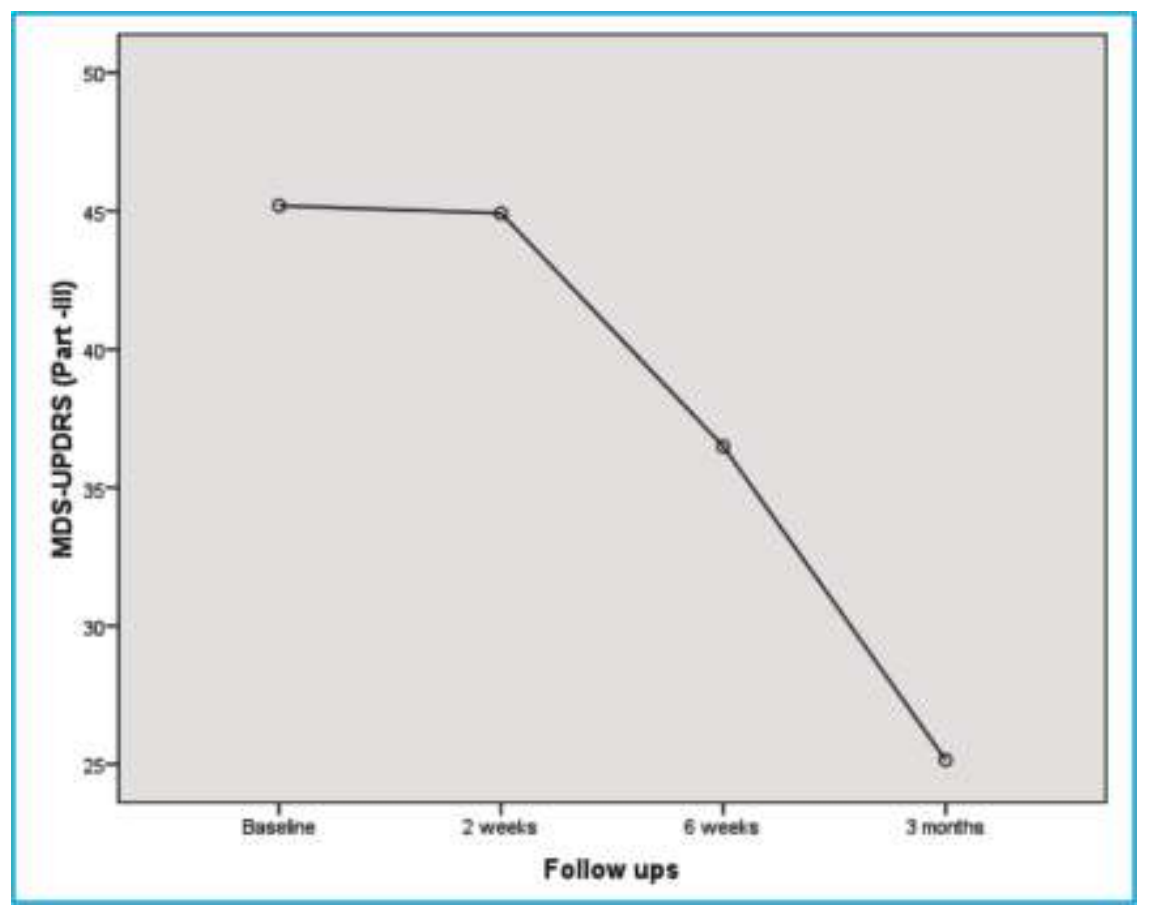

Figure 3: Graphical Comparison of MDS-UPDRS (part-III) score at different follow-ups. 
At baseline, the mean MDS UPDRS (part-IV) score was 10.18 \pm 0.87 , at $2^{\text {nd }}$ week, the score was $9.83 \pm 0.59$, at $6^{\text {th }}$ week, the score was $5.93 \pm 1.43$ and at the end of $3^{\text {rd }}$ month, the mean score was $3.85 \pm 1.03$, respectively. There was significant reduction in MDS-UPDRS score when compared with different followups, $p$-value $<0.05$ except baseline versus 2 weeks, $p$-value $>0.05$. Overall the decrease in MDS-UPDRS score (Part-IV) was statistically significant.
Table 7: Comparison of MDS-UPDRS (part-IV) score at different followups.

\begin{tabular}{lrrrcc|} 
MDS-UPDRS (part-IV) & Mean & S.D & Range & Minimum & Maximum \\
At baseline & 10.18 & 0.87 & 2.20 & 9.00 & 11.20 \\
At 2 weeks & 9.83 & 0.59 & 1.80 & 9.00 & 10.80 \\
At 6 weeks & 5.93 & 1.43 & 3.80 & 4.20 & 8.00 \\
At 3 month & 3.85 & 1.03 & 3.30 & 2.20 & 5.50 \\
\hline
\end{tabular}

Table 8: Comparison of MDS-UPDRS (part-IV) score at different followups (F-test $=3552.273$ ).

\begin{tabular}{lccc|} 
MDS-UPDRS (part-IV) & $\mathbf{t}$ & $\mathbf{d f}$ & p-value \\
\hline Baseline versus 2 weeks & 1.111 & 14 & 0.285 \\
Baseline versus 6 weeks & 12.131 & 14 & $<0.001$ \\
Baseline versus 3 months & 18.984 & 14 & $<0.001$ \\
2 weeks versus 6 weeks & 7.747 & 14 & $<0.001$ \\
2 weeks versus 12 months & 15.916 & 14 & $<0.001$ \\
6 weeks versus 12 months & 5.857 & 14 & $<0.001$
\end{tabular}

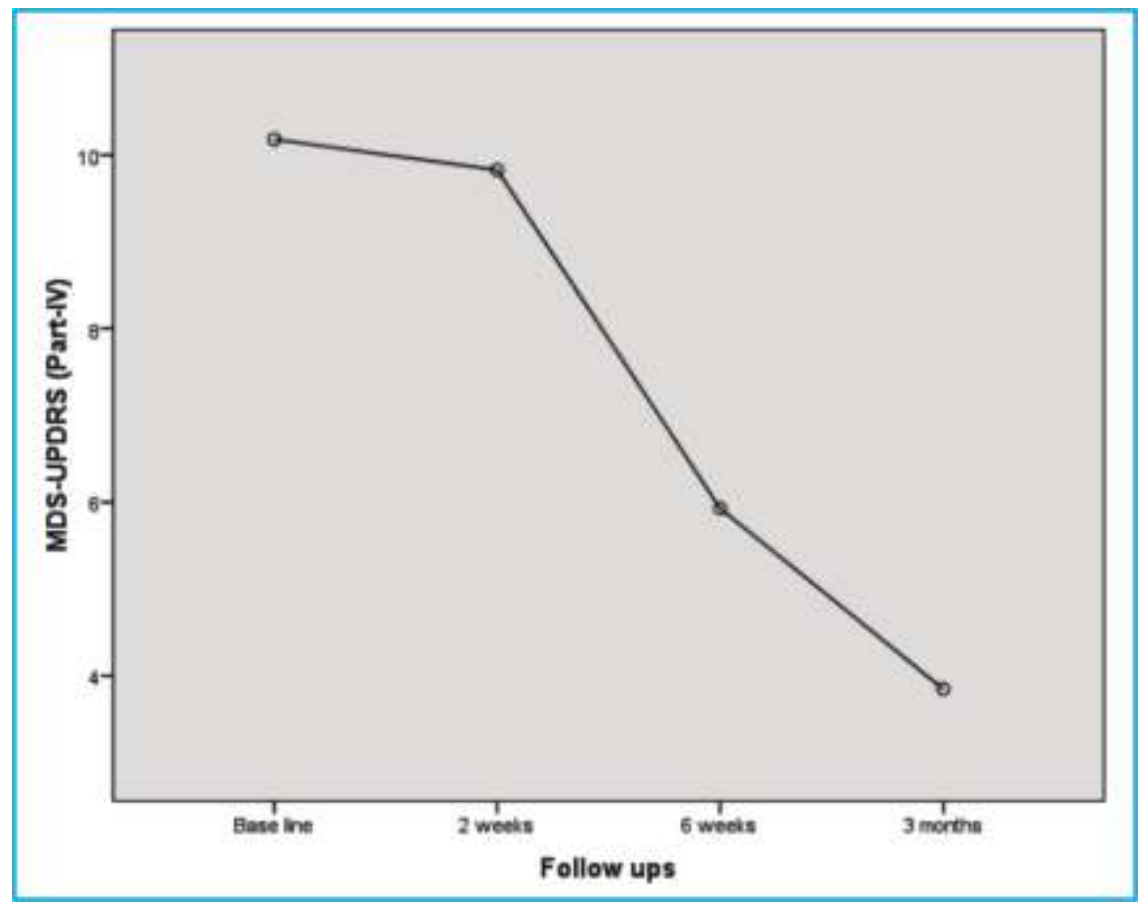

Figure 4: Graphical Comparison of MDS-UPDRS (part-IV) score at different follow-ups. 


\section{DISCUSSION}

PD is an aging disease. Bilateral DBS for advanced Parkinsonism is an effective treatment for controlling motor symptoms, including motor variations and dyskinesia. ${ }^{13}$ MDS-UPDRS is an effective way to determine the effect of motor as well as non-motor aspect of the disease process, as it's been documented that there are some non-motor symptoms like depression and cognition which are also significant. Recently Movement Disorder Society has established new revised questionnaire. ${ }^{9}$ The new questionnaire measures the efficacy of the treatment more precisely. ${ }^{6,9}$ The MDS-UPDRS Part I, In Parkinson's disease measures the score of non-motor symptoms. Another study ${ }^{7}$ shows improvement in MDS UPDRS I. In this study at baseline the mean MDS - UPDRS (Part-I) score was $13.8 \pm 6.3$ and at the end of 6 months the mean score was $10.7 \pm$ 4.7 respectively.

In the current study, at baseline, the mean MDS - UPDRS (Part-I) score was $14.20 \pm 0.61$ and at the end of $3^{\text {rd }}$ month the mean score was 11.18 \pm 0.47 , respectively. Overall the decrease in MDSUPDRS score (Part-I) was statistically significant (Tables $1 \& 2$ ).

Chou et al ${ }^{7}$ showed animprovement in MDS UPDRS II. In this study, at baseline the mean MDS - UPDRS (Part-II) score was $18.4 \pm 8$ and at the end of 6 months the mean score was $13.4 \pm$ 16.6 , respectively.

In the current study, at baseline, the mean MDS - UPDRS (part-II) score was $18.99 \pm 0.70$ and at the end of $3^{\text {rd }}$ month, the mean score was $13.01 \pm 0.57$, respectively. Overall, the decrease in MDS-UPDRS score (Part-II) was statistically significant (Tables $3 \& 4$ ).

Another study shows UPDRS III after STN stimulation procedure and on medications was reduced to $15.9 \pm 12.2$ at one year follow-up while on baseline it was $56.7 \pm 15.7$. $^{8}$

Chou et $\mathrm{al}^{7}$ showed an improvement in MDS UPDRS III. In this study at baseline the mean
MDS - UPDRS (Part-III) score was $45.6 \pm 16.6$ (Off Medication) and at the end of 6 months, the mean score was $25.3 \pm 12.5$ (On stimulation/On Medication) respectively.

In comparison to our study, at baseline, the mean MDS - UPDRS (part-III) score was $45.19 \pm$ 0.90 (off Medication) and at the end of $3^{\text {rd }}$ month, the mean score was $25.15 \pm 1.20$ (On Medication). Overall, the decrease in MDS-UPDRS score (PartIII) was statistically significant (Tables 5 \& 6).

Chou et $\mathrm{al}^{7}$ observed an improvement in MDS UPDRS IV. In this study, at baseline, the mean MDS - UPDRS (Part-IV) score was $9.6 \pm 4.4$ and at the end of 6 months, the mean score was $2.5 \pm$ 2.3, respectively.

At baseline, the mean MDS - UPDRS (part-IV) score was $10.18 \pm 0.87$ and at the end of $3^{\text {rd }}$ month, the mean score was $3.85 \pm 1.03$ respectively, (Tables $7 \& 8$ ). Overall, the decrease in MDS-UPDRS score.

Regarding complication in our study, there was one patient (6.67\%) who hadan intracerebral hemorrhage which resolved over a month. It was picked-up by the neurologist with deterioration of the power and the procedure was abandoned.

Levi et al. $(2015)^{16}$ reported that the 90-day post-operative mortality rate was $0 \%$. Incidence of complications related to surgery was 6, (54\%). In the elderly group, they observed 3 postoperatives $\mathrm{ICH}$ 7, (89\%), 1 requiring urgent surgical evacuation. In the younger group, 2 postoperative asymptomatic $\mathrm{ICH} \mathrm{2,} \mathrm{(89 \% )} \mathrm{and} 2$ wound infections 2, (89\%).

As per Kim et al (2017), ${ }^{3}$ the infection occurred in $5 \%$ of all DBS medical procedures and in $7 \%$ of all PD patients who underwent DBS. Most Infections (75\%) were within 3 months after the DBS procedure.Gram-positive microscopic organisms were the most widely recognized pathogens (75\%).

In an investigation done by Fernández-Pajarín, et al (2017), ${ }^{15}$ it was found that the pulse generator being the most widely recognized area 
for infection. Lead breaks (9.3\%) are the second most common complexity. Symptomatic peri-lead edema and blister formation were extraordinary.

In our study of Parkinson disease, patients significantly improved after bilateral STN DBS not only in their motor component, but also the nonmotor components which improved their quality of life. In our study, we used a MDS UPDRS scoring system previously there was the UPDRS scoring system, which is more popular but, the drawback is that it addresses more motor symptoms as compared to non-motor symptoms of the disease. In our study, there are certain limitations which include a less number of patients, which is definitely due to the cost of the procedure and secondly, we assessed postoperative patient with stimulation and on medications as patient were reluctant to off their stimulation after getting beneficial effect so we have to assess patient on Med/On Stim. With the help of neurologist we followed the patient well.

Beyond the scope of this study, we also found that with STN DBS the dosage requirement of the Anti-Parkinson's medicines were reduced significantly. Those Patients who presented with drug related Dyskinesia specially got benefited by the STN DBS due to a reduction in the doses.

This study encouraging for the treatment of advanced Parkinson's disease surgically as patients showed significant improvement in both non motor and motor symptoms with a low complication rate.

\section{CONCLUSION}

It is concluded that deep brain stimulation (DBS) improved symptoms, as assessed by the reduction in MDS-UPDRS. And also the need for medications is reduced (but they are required). Hence, this procedure should be opted for such a significant health issue to improve the symptoms in our setups.

\section{REFERENCES}

1. Elbaz A, Carcaillon L, Kab S.Moisan F. Epidemiology of Parkinson's disease. Rev Neurol. 2016; 172: 1426.

2. Chen, S-Y, Tsai, S-T. The Epidemiology of Parkinson's Disease. Tzu ChiMedical Journal, 2010; 22: 73-81.

3. Pouratian N, Thakkar, S Kim, W Bronstein, J. M. Deep brain stimulation for the treatment of Parkinson's disease efficacy and safety. Degenerative Neurol Neuromuscular Dis, 2012: 1 16.

4. Benabid AL, Chabardes S. SeigneuretE. Deep-brain stimulation in Parkinson's disease: long-term efficacy and safety - What happened this year? Curr Opin Neurol. 2005; 18: 623-30.

5. Follett K. A, Weaver F. M, Stern M, Hur K, Harris, C. L Luo, P.Marks Jr, W. J. Rothlind, J. Sagher, O. Moy C. Pallidal versus subthalamic deep-brain stimulation for Parkinson's disease. N Engl J Med. 2010; 362: 2077-2091.

6. Fahn S. Unified Parkinson's disease rating scale. J Parkinsons Dis. 1987.

7. Kelvin L. Chou, Jennifer L. Taylor, Parag G. Patil, The MDS-UPDRS tracks motor and non-motor improvement due to subthalamic nucleus deep brain stimulation in Parkinson disease Parkinsonism Relat Disord. 2013; 19 (11).

8. Rodriguez-Oroz, M Obeso, J Lang, Houeto, J.-L, Pollak, P. Rehncrona, et al. Bilateral deep brain stimulation in Parkinson's disease: a multicentre study with 4 years follow-up. Brain, 2005; 128 : 2240-2249.

9. Goetz CG. Tilley BC. Shaftman SR. Stebbins GT, Fahn, S. et al. Movement Disorder Society sponsored revision of the Unified Parkinson's Disease Rating Scale (MDS - UPDRS): scale presentation and clinimetric testing results. Mov Disord. 2008; 23: 2129-2170.

10. Zesiewicz T. Sullivan, K. Arnulf, I. Chaudhuri, K. Morgan JC, et al.W Practice parameter: treatment of nonmotor symptoms of Parkinson disease report of the quality standards subcommittee of the american academy of neurology. Neurology, 2010; 74: 924-931.

11. Jafari, N. Pahwa, R. Nazzaro, J. M. Arnold, P. M. Lyons K. E. MDS-UPDRS to assess non-motor symptoms after STN DBS for Parkinson's disease. 
International Journal of Neuroscience, 2016; 126: 25-29.

12. Krause $M$, Fogel W Heck, A Hacke, W Bonsanto, M Trenkwalder, C. Tronnier V. Deep brain stimulation for the treatment of Parkinson's disease: subthalamic nucleus versus globus pallidus internus. J Neurol Neurosurg Psychiatry, 2001; 70: 464-470.

13. Castrioto A. Lozano AM. Poon Y-Y. Lang A., Fallis $M$, Moro E. Ten-year outcome of subthalamic stimulation in Parkinson disease: a blinded evaluation. Arch Neurol. 2011; 68: 1550-1556.
14. Ashis Kumar, Kakkar, Neha Dahiya, Management of Parkinson's Disease: Current and future Pharmacotherapy. Eur J Pharmac. 2015; 750: 74-81.

15. Fernández FS, Alvarez Vega MA, Antuña Ramos $A$, Fernández González F, Lozano Aragoneses B. Lead fractures in deep brain stimulation during longterm follow-up. Parkinson's Disease, 2010; 2010.

16. Levi V, Carrabba G, Rampini P, Locatelli M. Short term surgical complications after subthalamic deep brain stimulation for Parkinson's disease: does old age matter? BMC geriatrics, 2015; 15 (1): 116.

\section{Additional Information}

Disclosures: Authors report no conflict of interest.

Ethical Review Board Approval: The study was conformed to the ethical review board requirements.

Human Subjects: Consent was obtained by all patients/participants in this study.

Conflicts of Interest:

In compliance with the ICMJE uniform disclosure form, all authors declare the following:

Financial Relationships: All authors have declared that they have no financial relationships at present or within the previous three years with any organizations that might have an interest in the submitted work.

Other Relationships: All authors have declared that there are no other relationships or activities that could appear to have influenced the submitted work.

\section{AUTHORS CONTRIBUTIONS}

\begin{tabular}{|l|l|l|}
\hline Sr.\# & Author's Full Name & Intellectual Contribution to Paper in Terms of: \\
\hline 1. & Khalid Mahmood & 1. Study design and methodology. \\
\hline 2. & Omair Afzal Ali & 2. Paper writing, referencing, and data calculations. \\
\hline 3. & Adeeb-ul-Hassan & 3. Data collection and calculations. \\
\hline 4. & Imran Ali & 4. Analysis of data and interpretation of results. \\
\hline
\end{tabular}

